\title{
Unfavorable clinical implications for hypermethylation of RUNX3 in patients with salivary gland adenoid cystic carcinoma
}

\author{
MING-HUA GE ${ }^{1}$, CHAO CHEN ${ }^{1}$, JIA-JIE XU ${ }^{1}$ and ZHI-QIANG LING ${ }^{2}$ \\ ${ }^{1}$ Department of Surgical Oncology and ${ }^{2}$ Zhejiang Cancer Research Institute, \\ Zhejiang Province Cancer Hospital, Hangzhou 310022, P.R. China
}

Received February 21, 2011; Accepted April 8, 2011

DOI: $10.3892 /$ or.2011.1282

\begin{abstract}
To elucidate the potential etiological role of RUNX3 in the development of salivary gland adenoid cystic carcinoma (ACC), we analyzed the methylation status of RUNX3 in a series of 114 ACC tissues and 3 ACC cell lines. Results showed that the methylated rate of RUNX3 was 50.9 and $3.5 \%$ in the 114 ACC samples and the corresponding normal salivary glands, respectively, achieving a significant difference $(\mathrm{P}<0.001)$. There was a significant correlation between RUNX3 methylation and various clinicopathological parameters of ACCs, such as perineural invasion, lymph node involvement, T-stage and distant metastasis $(\mathrm{P}<0.001)$. RUNX3 methylation was a significant predictor of the 5-year disease-free survival in ACC patients after surgery. Partial methylation was found in all 3 ACC cell lines, and the reactivation and more potent expression of RUNX3 was induced by 5-triazole-2-deoxycytidine. Our findings indicate that RUNX3 methylation may occur as a common event in the development of ACC and that methylation may be a major mechanism for inactivation of RUNX3 in ACC.
\end{abstract}

\section{Introduction}

Human salivary gland adenoid cystic carcinoma (ACC), a common malignant tumor in the oral and maxillofacial region, is characterized by high invasiveness, high incidence of neurological and vascular invasion, high local recurrence and high lung and other metastases; these clinical biological features are the main prognostic factors leading to reduced survival in patients (1-5). Surgery and radiotherapy are currently used to treat this malignancy $(6,7)$. Studies have revealed that abnormal expression of cell adhesion and proliferation-associated genes

Correspondence to: Professor Zhi-Qiang Ling, Zhejiang Cancer Research Institute, Zhejiang Province Cancer Hospital, Hangzhou 310022, P.R. China

E-mail: lingzq@hotmail.com

Key words: human salivary gland adenoid cystic carcinoma, runt-related transcription factor-3, methylation, real-time methylationspecific PCR, Western blotting, disease-free survival are relevant to the high invasiveness of this malignancy, but the actual mechanism behind this characteristic remains to be clarified. Human runt-related transcription factor-3 (RUNX3), a tumor-suppressor gene newly discovered in gastric carcinoma, is located on chromosome 1p36. It plays an important role in human embryonic development and in the genesis and development of various types of tumors and is closely related to invasion and metastasis (8-15). In TGF- $\beta$-mediated cell apoptosis signaling pathways, RUNX3 is an important downstream regulatory factor. If RUNX3 is inactivated, TGF- $\beta$ fails to promote apoptosis and inhibit proliferation, leading to abnormal cell proliferation or tumor formation $(8,16-18)$. Studies have shown that promoter methylation and loss of heterozygosity $(\mathrm{LOH})$ are the major causes for inactivation of RUNX3; in some tumors, acquired promoter methylation and histone deacetylation of suppressor genes are associated with the genesis and development of tumors, and the degree of methylation of tumor-suppressor genes is associated with patient prognosis (19-24). Studies have shown that the methylation of certain tumor-suppressor genes, cell adhesion-associated genes and cell cycle-associated genes is associated with the genesis of ACC (25-27).

ACC-2 and ACC-3 cell lines established in 1988 maintain the characteristics of ACC and ACC-M cell lines, which are characterized by high pulmonary metastasis and are screened from ACC-2 lines. These cell lines (ACC-2, -3 and -M) provide a basis for experiments to study the biological features and the molecular mechanism of ACC invasion and metastasis (27-29). 5-Aza-deoxycytidine (5-Aza-dC), a reverse transcriptase of DNA methylation, can reverse DNA methylation in vitro. There are currently no reports regarding RUNX3 expression in ACC-2, ACC-M and ACC-3 cell lines, and it has not been clarified whether the use of 5-Aza-dC improves RUNX3 expression in ACC-2, ACC-M and ACC-3 cells. In this study, we detected RUNX3 expression in ACC-2, ACC-M and ACC-3 cell lines treated with 5-Aza-dC by RT-PCR and Western blotting, and we determined the cellular localization of RUNX3 protein after 5-Aza-dC treatment by laser scanning confocal microscope (LSCM), thus providing experimental evidence for studying the mechanism of RUNX3 in ACC. Furthermore, we studied RUNX3 promoter methylation using real-time methylation-specific PCR (real-time MSP) in ACC tissue 
samples and explored the clinical significance of RUNX3 methylation in ACC.

\section{Materials and methods}

Tissue samples. One hundred and fourteen samples of resected ACC were collected; 91 samples were paraffin-embedded and 23 samples were immediately placed in liquid nitrogen after removal. The samples were collected from 54 males and 60 females, aged 23-81 years (median age 55 years). There were 51 cases of cribriform pattern carcinoma, 24 cases of salivary duct carcinoma and 39 cases of solid carcinoma. According to the general rules of ACC staging suggested by the International Union Against Cancer (UICC, 2002) (30), there were 53 cases of stage T1-3 and 61 cases of stage T4. Normal salivary gland tissues (NSGs) served as controls. Routinely, all the resected specimens were histologically examined by hematoxylin and eosin (H\&E) staining. The protocol was approved by the Zhejiang Province Cancer Hospital Ethics Committee.

Cell culture and treatment. The ACC-2, ACC-M and ACC-3 cell lines were donated by the Shanghai Ninth People's Hospital affiliated with Shanghai Jiaotong University. ACC-2, ACC-M and ACC-3 cells were cultured in RPMI-1640 medium containing $10 \%$ fetal bovine serum (FBS), $100 \mathrm{U} / \mathrm{ml}$ of penicillin and streptomycin at $37^{\circ} \mathrm{C}$ in $5 \% \mathrm{CO}_{2}$. After the cells reached $80 \%$ confluency, they were digested with $0.25 \%$ trypsin and passaged for subculture; $24 \mathrm{~h}$ later, the cells were supplemented with 5 -Aza-dC to a final concentration of $300 \mathrm{nmol} / 1$ and continuously cultured for three days. Prior to use, cells were digested with $0.25 \%$ trypsin, rinsed three times with $4^{\circ} \mathrm{C}$ PBS, precipitated at $4^{\circ} \mathrm{C}$, centrifuged at $<2000 \mathrm{x}$ g for $1 \mathrm{~min}$, and were suspended in PBS at a cell density of $1 \times 10^{6} / \mathrm{ml}$. Total RNA and protein were extracted and stored at $-70^{\circ} \mathrm{C}$ until use.

RNA extraction and reverse transcription. Total RNA was extracted using TRIzol (Gibco) from 1x10 ${ }^{6}$ ACC-2, ACC-M or ACC-3 cells treated with 5-Aza-dC or left untreated. RNA was dissolved in $25 \mu \mathrm{l}$ of DNase/RNase-free $\mathrm{ddH}_{2} \mathrm{O}$ treated with DEPC, and RNase inhibitors $\left(\mathrm{RNasin}^{\circledR}\right)$ were added to a final concentration of $1 \mathrm{U} / \mu \mathrm{l}$. Genomic DNA contamination in total RNA was digested with RNase-free DNase I. cDNA was synthesized using $1 \mu \mathrm{g}$ of total RNA templates as previously described (31). Some cancer cells and matching normal salivary gland tissues were microdissected from the frozen tissue in 19 ACC cases with the LM100 laser capture microdissection system (Arcturus Engineering Inc., Mountain View, CA, USA). Extraction of total RNA from the dissected cells of the tumor and non-tumor specimens, removal of genomic DNA contamination and cDNA synthesis were carried out following the same method as that used in the ACC cell lines.

DNA extraction and bisulfite modification. Genomic DNA was extracted from ACC-2, ACC-M and ACC-3 cells, which were either treated with 5-Aza-dC or left untreated, using the phenol-chloroform method (31). Paraffin sections (5-10) (7-10 $\mu \mathrm{m})$ were prepared and subjected to laser capture microdissection (LCM) using the LM200 LCM system (Arcturus Engineering Inc.). Trace DNA was extracted and purified by the proteinase $\mathrm{K}$ digestion method as previously reported
(31). DNA was modified using the bisulfite method following instructions in the EpiTect Bisulfite kit (Qiagen).

PCR amplification. Primers used to amplify cDNA of RUNX3 and $\beta$-actin in real-time RT-PCR were designed as previously described (32): RUNX3 (F) 5'-AGGCATTGCGCAGCTC AGCGGAGTA-3', (R) 5'-TCTGCTCCGTGCTGCCCTCGCA CTG-3' (153 bp); $\beta$-actin (F) 5'-AAATCTGGCACCACA CCTT-3', (R) 5'-AGCACTGTTGGCGTACAG-3' (646 bp). The primers for the methylated (M) and unmethylated (U) promoter regions of RUNX3 were obtained from a previous report(33).M:(F) 5'-TATTCGTTAGGGTTCGTTCGTTGC-3', (R) 5'-ACGACCGCGAACGAACTTCGAAAC-3' (201 bp); U: (F) 5'-TATTTGTTAGGGTTTGTTTGTTGT-3', (R) 5'-ACAACCACAAACAAACTTCAAAAC-3' (201 bp). Realtime RT-PCR and real-time MSP amplification and melting curve analyses were performed using LightCyler ${ }^{\circledR}$ FastStart DNA Master SYBR-Green Kit (Roche Diagnostics) in a Light Cycler $^{\circledR} 2.0$ (Roche) PCR instrument. The $2^{-\Delta \Delta C t}$ method was used for the relative quantitative analysis of RUNX3 mRNA in the three ACC cell lines. The concentration of methylated DNAs in the samples was calculated according to the $\mathrm{Ct}$ value and a standard curve. The methylation percentage was calculated as follows: $\mathrm{M} \%=100 \times$ (copy number of methylated DNA/the sum of the copy number of methylated and unmethylated DNA). The sum of the copy numbers of methylated and unmethylated DNAs was used as the total copy number of DNA of the target genes. M\% >75.0, 25.0-75.0 and <25.0 were considered as fully methylated (M), partially methylated (U/M) and unmethylated (U), respectively. PCR products were separated by $2.0 \%$ agarose gel electrophoresis and visualized by EB staining.

Analysis of the intracellular location of the RUNX3 protein detected by LSCM. Cells were digested with $0.25 \%$ trypsin, and $200 \mu \mathrm{l}$ per well were plated (at $2 \times 10^{3}$ cells/well) into 6-well plates containing aseptic cover slides on the bottom. ACC cells were inoculated, and when cells reached $60-80 \%$ confluency, the medium was discarded, and cells were treated with $300 \mathrm{nmol} / 1$ of 5-Aza-dC or left untreated as noted above. Cells were then washed with PBS for $10 \mathrm{~min}$, fixed in formaldehyde for $5 \mathrm{~min}$, then washed again with PBS for $10 \mathrm{~min}$. Cells were treated with Triton X-100 (0.1\% v/v) for $5 \mathrm{~min}$ and washed with PBS. Goat serum (1\%) was added and incubation was carried out for 20 min. Goat anti-human RUNX3 polyclonal antibody (diluted $\mathrm{x} 30$; R\&D Systems Inc., USA) was added and incubation was carried out for $1 \mathrm{~h}$ at $37^{\circ} \mathrm{C}$. Cells were washed three times in PBS, exposed for $1 \mathrm{~h}$ to rhodamine-labeled rabbit anti-goat secondary antibody (diluted x30, Caltag Laboratories, USA) at $37^{\circ} \mathrm{C}$ and were washed three times in PBS. Protein expression was detected using LSCM (Leica TCS-NT, Germany). The parameters included an excitation wave length of $567 \mathrm{~nm}$, xyzaxis scanning, a laser power of $20 \pm 2 \mathrm{~mW}$, a scanning intensity of $50 \%$, a PMT of 852 , a detect pinhole of 2.02 and scanning frequency of four. Thirty random cells from each sample were selected for the detection of fluorescence intensity, and each experiment was repeated three times.

Western blot analysis. ACC-2, ACC-M and ACC-3 cells treated with 5-Aza-dC or left untreated were collected, with 
5-Aza-dC treatment (-) Marker ACC-2 ACC-M ACC-3

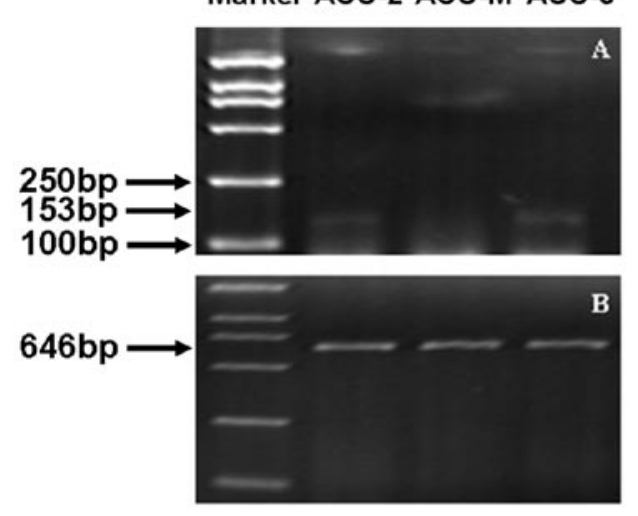

5-Aza-dC treatment (+)

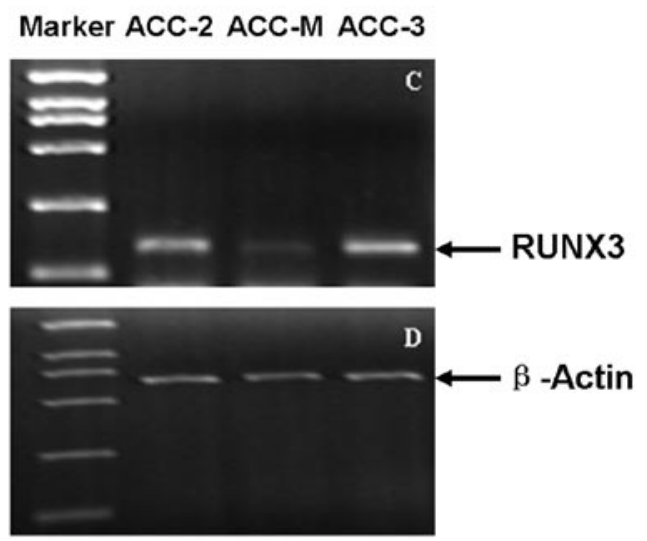

Figure 1. Real-time RT-PCR analysis of RUNX3 mRNA in ACC-2, ACC-M and ACC-3 cells with or without 5-Aza-dC treatment (M, DNA marker DL2000). (A) Electrophoresis of RUNX3 mRNA in ACC-2, ACC-M and ACC-3 without 5-Aza-dC treatment. (B) Electrophoresis of $\beta$-actin mRNA in ACC-2, ACC-M and ACC-3 without 5-Aza-dC treatment. (C) Electrophoresis of RUNX3 mRNA in ACC-2, ACC-M and ACC-3 after $300 \mathrm{nmol} / 1$ 5-Aza-dC treatment for $72 \mathrm{~h}$. (D) Electrophoresis of $\beta$-actin mRNA in ACC-2, ACC-M and ACC-3 after $300 \mathrm{nmol} / 15$-Aza-dC treatment for $72 \mathrm{~h}$.

cell counts of $1 \times 10^{6}$. Cell lysis buffer was added at a volume equal to six times that of the cell pellet. Total protein was extracted and then quantified using the Lowry method (34). After real-time MSP and RT-PCR analysis, 19 frozen specimens with sufficient tissue for detection were used for Western blot analysis. ACC and adjacent normal tissues $(150 \mathrm{mg}$ of each) were collected, cleaned by washing with physiological saline and cut into pastes. Protein was extracted and quantified using the same method described above. Protein was electroblotted to a nitrocellulose membrane (NC membrane), fresh rabbit anti-human RUNX3 polyclonal antibody (R\&D Systems Inc.) was added, and the blot was incubated overnight at $4^{\circ} \mathrm{C}$. The NC membrane was washed, and fresh alkaline phosphatase-labeled goat anti-rabbit IgG (R\&D Systems Inc.) was added. The blot was incubated for $2 \mathrm{~h}$ at room temperature. After the membrane was rinsed, the color was developed using a staining solution, and the reaction was terminated. $\beta$-tubulin monoclonal antibody (Mr 51000, Takara) served as an inner control. Images were captured by an Epson color image scanner and were analyzed by Image-Pro Plus software (version 5.1; Media Cybernetics, USA). The $\beta$-tubulin protein grayscale was used for calibration, and the relative amount of protein was calculated.

Statistical analysis. SPSS 14.0 statistical software was utilized. Count data comparison between groups was carried out using the $\chi^{2}$ test and those not in accord with $\chi^{2}$ test conditions were analyzed using Fisher's exact test. Measurement data comparison between groups used one-way ANOVA, and the results of the measurement data were stated as the mean \pm SEM. $\mathrm{P}<0.05$ indicated a statistically significant difference. Survival analysis was carried out by means of the Kaplan-Meier method, and significant levels were assessed by means of the log-rank test. A univariate analysis with the Cox regression model was used to determine prognostic factors, and multivariate analysis with the Cox regression model was used to explore combined effects. P-values $<0.05$ were considered to indicate statistical significance.

\section{Results}

Expression of RUNX3 mRNA in ACC-2, ACC-M and ACC-3 cells after 5-Aza-dC treatment. Prior to treatment with 5-Aza$\mathrm{dC}$, RUNX3 mRNA was present in the ACC-2 and ACC-3 cells but was not present in the ACC-M cells (Fig. 1A and B). After the cells were treated with 5-Aza-dC, the RUNX3 mRNA level was enhanced in both the ACC-2 and ACC-3 cells, and was also detected in the ACC-M cells (Fig. 1C and D). These results demonstrated that inhibition of RUNX3 mRNA expression might be associated with RUNX3 promoter methylation.

Correlation between RUNX3 methylation in ACC cells and clinicopathologic parameters. RUNX3 promoter 5 '-CpG islands were incompletely methylated in the ACC-2, ACC-M and ACC-3 cells, and the degree of methylation was 50, 75 and $33 \%$ in the ACC-2, ACC-M and ACC-3 cells, respectively. After cells were treated with 5-Aza-dC, RUNX3 was not methylated in the ACC-2, ACC-M and ACC-3 cells, indicating that methylation was reversed. The methylation status of RUNX3 was analyzed by real-time MSP in 114 samples of ACC cases. In ACCs and NSGs, the positive values of RUNX3 methylation were 50.9\% (58/114) and 3.5\% (4/114), respectively. These two levels were significantly different $(\mathrm{P}<0.001)$, suggesting that RUNX3 methylation plays an important role in the genesis of tumors. There was a significant correlation between RUNX3 methylation and various clinicopathological parameters of ACCs, such as perineural invasion, lymph node involvement, T-stage and distant metastasis (all $\mathrm{P}<0.001$ ). However, there was no significant correlation between the degree of RUNX3 methylation and gender, age at diagnosis, tumor site and histologic types of ACCs (all P>0.05) (Table I).

Effects of 5-Aza-dC on the expression of RUNX3 protein in ACC cells using LSCM analysis. RUNX3 protein was weakly expressed in the ACC-2, ACC-M and ACC- 3 cells, with the weakest expression in the ACC-M cells (Fig. 2). RUNX3 
Table I. Relationship between runt-related transcription factor-3 (RUNX3) methylation and clinicopathological parameters in 114 adenoid cystic carcinomas.

\begin{tabular}{|c|c|c|c|}
\hline $\begin{array}{l}\text { Clinicopathological } \\
\text { parameters }\end{array}$ & $\begin{array}{l}\text { No. of } \\
\text { cases }\end{array}$ & $\begin{array}{l}\text { Methylation } \\
(\%)^{\mathrm{a}}\end{array}$ & P-value \\
\hline \multicolumn{4}{|l|}{ Specimen } \\
\hline Tumor & 114 & $58 \quad(50.9)$ & $0.000^{\mathrm{b}}$ \\
\hline Normal & 114 & $4 \quad(3.5)$ & \\
\hline \multicolumn{4}{|l|}{ Gender } \\
\hline Male & 54 & $26(48.1)$ & 0.580 \\
\hline Female & 60 & $32(53.3)$ & \\
\hline \multicolumn{4}{|l|}{$\begin{array}{l}\text { Age at diagnosis } \\
\text { (years) }\end{array}$} \\
\hline$<57$ & 56 & $30 \quad(53.6)$ & 0.572 \\
\hline$\geq 57$ & 58 & $28 \quad(48.3)$ & \\
\hline \multicolumn{4}{|l|}{ Tumor site } \\
\hline Minor salivary gland & 70 & $36 \quad(51.4)$ & 0.882 \\
\hline Major salivary gland & 44 & $22 \quad(50.0)$ & \\
\hline \multicolumn{4}{|l|}{ Histologic types } \\
\hline Cribriform & 51 & $25 \quad(49.0)$ & 0.898 \\
\hline Tubular & 24 & $12(50.0)$ & \\
\hline Solid & 39 & $21 \quad(53.8)$ & \\
\hline \multicolumn{4}{|l|}{ Perineural invasion } \\
\hline Negative & 54 & 14 (25.9) & $0.000^{\mathrm{b}}$ \\
\hline Positive & 60 & $44 \quad(73.3)$ & \\
\hline \multicolumn{4}{|l|}{ Lymph node } \\
\hline \multicolumn{4}{|l|}{ involvement } \\
\hline N0 & 95 & $39(41.1)$ & $0.000^{\mathrm{b}}$ \\
\hline $\mathrm{N}+$ & 19 & $19(100.0)$ & \\
\hline \multicolumn{4}{|l|}{ T-stage } \\
\hline $\mathrm{T} 1-3$ & 53 & $13(24.5)$ & $0.000^{\mathrm{b}}$ \\
\hline $\mathrm{T} 4$ & 61 & $45 \quad(73.8)$ & \\
\hline \multicolumn{4}{|l|}{ Distant metastasis } \\
\hline Negative & 99 & 43 (43.4) & $0.000^{\mathrm{b}}$ \\
\hline Positive & 15 & $15(100.0)$ & \\
\hline
\end{tabular}

anclude fully methylated (M) and partially methylated (U/M) cases. ${ }^{\mathrm{b} S t a t i s t i c a l l y ~ s i g n i f i c a n t . ~}$

protein was observed in the cytoplasm of the ACC-2 (Fig. 2A) and ACC-M (Fig. 2B) cells but was not observed in the nuclei of either cells. RUNX3 protein was weakly observed in both the nucleus and the cytoplasm of ACC-3 cells (Fig. 2C). After all the cells were treated with 5-Aza-dC, positive RUNX3 protein signals were enhanced and observed in the nucleus of ACC-2 cells (Fig. 2D), and was also increased in ACC-M (Fig. 2E) and ACC-3 (Fig. 2F) cells. Levels of RUNX3 protein remained lowest in the ACC-M cells.

RUNX3 expression detected by Western blot analysis. As shown in Fig. 3, RUNX3 protein expression was noted in the ACC-2 and ACC-3 cells, and the RUNX3/GAPDH relative levels were 0.61 and 0.65 for ACC-2 and ACC-3 cells, respectively.

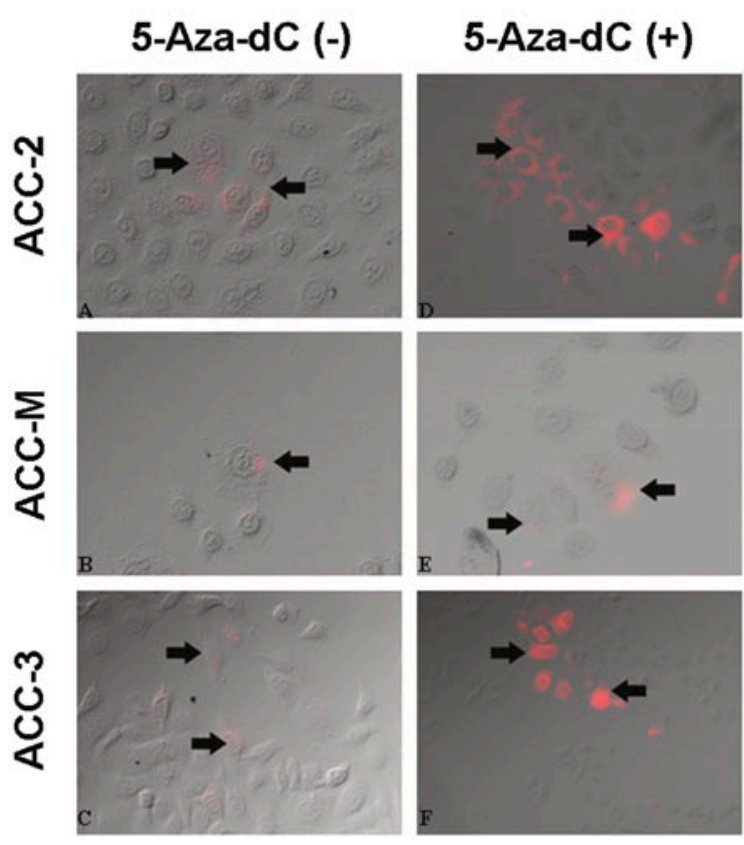

Figure 2. LSCM results of RUNX3 protein in ACC-2, ACC-M and ACC-3 cells with or without 5-Aza-dC treatment. (A) ACC-2 cells without 5-Aza-dC treatment. (B) ACC-2 cells treated with $300 \mathrm{nmol} / 15$-Aza-dC for $72 \mathrm{~h}$. (C) ACC-M cells without 5-Aza-dC treatment. (D) ACC-M cells treated with $300 \mathrm{nmol} / 1$ 5-Aza-dC for $72 \mathrm{~h}$. (E) ACC-3 cells without 5-Aza-dC treatment. (F) ACC-3 cells treated with $300 \mathrm{nmol} / 1$ 5-Aza-dC for $72 \mathrm{~h}$.
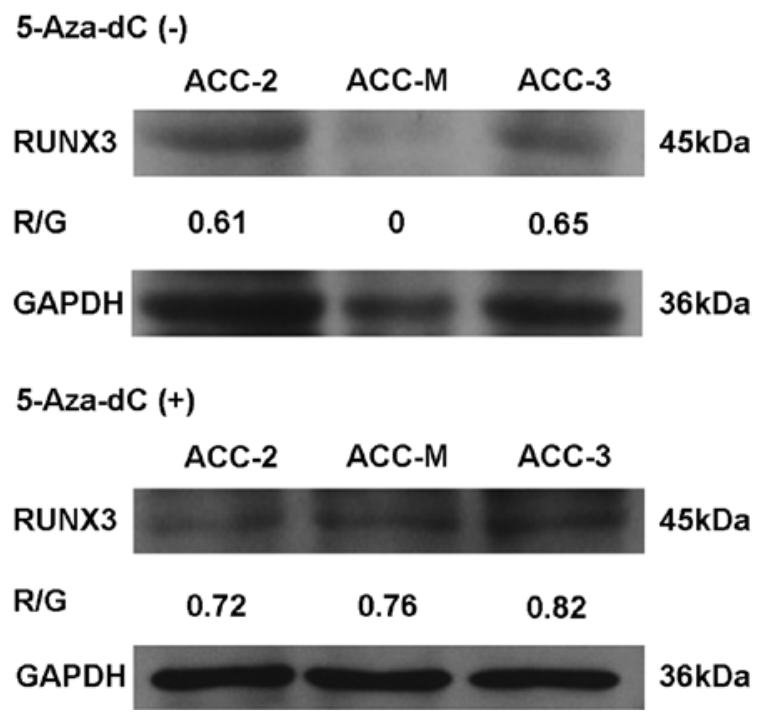

Figure 3. Western blotting results of RUNX3 in ACC-2, ACC-M and ACC-3 cells with or without 5-Aza-dC treatment. $\mathrm{R} / \mathrm{G}$ represents the brightness ratio of the RUNX3 protein (45 kDa) vs. GAPDH (36 kDa).

RUNX3 protein was not expressed in the ACC-M cells. After cells were treated with 5-Aza-dC, RUNX3 protein expression in the ACC-2 and ACC-3 cells was slightly increased, and the RUNX3/GAPDH relative levels were 0.72 and 0.82 , respectively. ACC-M cells treated with 5-Aza-dC also expressed RUNX3 protein, with a RUNX3/GAPDH relative level of 0.76 . These findings suggest that inhibition of RUNX3 expression may be associated with RUNX3 promoter methylation. These results were consistent with the LSCM results. Western blotting 
Table II. Relationship among runt-related transcription factor-3 (RUNX3) methylation, protein expression and mRNA expression in 19 frozen adenoid cystic carcinoma specimens.

\begin{tabular}{|c|c|c|c|}
\hline No. of cases & $\begin{array}{l}\text { Protein expression by } \\
\text { Western blotting }(\mathrm{T} / \mathrm{N})\end{array}$ & $\begin{array}{c}\text { mRNA expression by } \\
\text { RT-PCR }(\mathrm{T} / \mathrm{N})\end{array}$ & Methylation status ${ }^{\mathrm{a}}$ \\
\hline 1 & $0.476(0.377 / 0.792)$ & $0.462(0.072 / 0.156)$ & $\mathbf{U} / \mathbf{M}$ \\
\hline 2 & $0.955(0.835 / 0.874)$ & $1.033(0.062 / 0.060)$ & $\mathrm{U}$ \\
\hline 3 & $0.646(0.512 / 0.793)$ & $0.529(0.063 / 0.119)$ & $\mathbf{U} / \mathbf{M}$ \\
\hline 4 & $0.965(0.697 / 0.722)$ & $0.808(0.270 / 0.334)$ & $\mathrm{U}$ \\
\hline 5 & $0.561(0.478 / 0.852)$ & $0.651(0.162 / 0.249)$ & $\mathbf{U} / \mathbf{M}$ \\
\hline 6 & Not detected & Not detected & \\
\hline 7 & $0.124(0.115 / 0.931)$ & $0.208(0.085 / 0.409)$ & M \\
\hline 8 & $0.489(0.423 / 0.865)$ & $0.536(0.156 / 0.291)$ & $\mathbf{U} / \mathbf{M}$ \\
\hline 9 & Not detected & Not detected & \\
\hline 10 & $0.366(0.312 / 0.853)$ & $0.269(0.392 / 1.455)$ & M \\
\hline 11 & $0.286(0.128 / 0.447)$ & $0.128(0.082 / 0.640)$ & $\mathbf{M}$ \\
\hline 12 & Not detected & Not detected & \\
\hline 13 & $1.168(0.674 / 0.577)$ & $0.938(0.285 / 0.304)$ & $\mathrm{U}$ \\
\hline 14 & Not detected & Not detected & \\
\hline 15 & $0.690(0.533 / 0.773)$ & $0.561(0.369 / 0.658)$ & $\mathbf{U} / \mathbf{M}$ \\
\hline 16 & $0.438(0.382 / 0.873)$ & $0.429(0.666 / 1.552)$ & $\mathbf{M}$ \\
\hline 17 & $0.863(0.778 / 0.902)$ & $0.872(0.342 / 0.392)$ & U \\
\hline 18 & $0.504(0.446 / 0.885)$ & $0.572(0.451 / 0.789)$ & $\mathbf{U} / \mathbf{M}$ \\
\hline 19 & $0.370(0.323 / 0.874)$ & $0.362(0.243 / 0.672)$ & $\mathbf{M}$ \\
\hline 20 & $0.253(0.126 / 0.499)$ & $0.216(0.059 / 0.273)$ & $\mathbf{M}$ \\
\hline 21 & $0.954(0.638 / 0.669)$ & $1.069(0.822 / 0.769)$ & $\mathrm{U}$ \\
\hline 22 & $0.902(0.795 / 0.881)$ & $0.921(0.383 / 0.416)$ & $\mathrm{U}$ \\
\hline 23 & $0.728(0.665 / 0.913)$ & $0.788(0.149 / 0.189)$ & $\mathrm{U}$ \\
\hline
\end{tabular}

Bold print indicates that RUNX3 methylation was consistent with the down-regulation of RUNX mRNA and protein expression in ACC specimens. This consistency was higher in $\mathrm{U} / \mathrm{M}$ than in $\mathrm{M}$. M, methylation; $\mathrm{U} / \mathrm{M}$, partly methylation; $\mathrm{U}$, unmethylation.

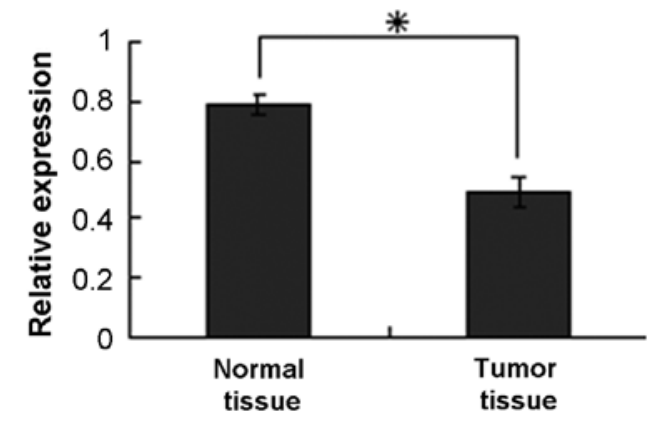

Figure 4. The relative expression of RUNX3 protein in primary salivary gland adenoid cystic carcinoma compared to that in normal salivary gland adenoid cystic tissue $\left({ }^{*} \mathrm{P}<0.001\right)$.

results based on 19 cases of ACC showed that the relative quantity of RUNX3 protein expression was $0.79 \pm 0.03$ in the NSCs but $0.49 \pm 0.05$ in the ACC cases. Statistical analysis showed that the expression of RUNX3 protein in the ACCs was significantly lower than that in the NSGs $(\mathrm{P}<0.001)$ (Fig. 4).
Correlation between RUNX3 methylation, protein expression and clinicopathologic parameters. In 19 cases, the degree of RUNX3 methylation in ACCs was consistent with the down-regulation of RUNX3 mRNA and protein expression (Table II). These results suggest that RUNX3 methylation may be a key control mechanism of RUNX3 silencing during ACC progression. Protein expression and metastasis $(\mathrm{P}=0.012)$ were significantly related to $\mathrm{T}$ staging $(\mathrm{P}=0.02)$, and RUNX3 protein expression in metastatic ACCs was significantly higher than in those without metastases (Table III).

Survival analysis. Using univariate analysis (Cox's regression model), RUNX3 methylation was found to be significantly associated with a worse prognosis $(\mathrm{P}=0.009)$, and age had a weak association with overall survival $(\mathrm{P}=0.110)$ (Table IV). The 5-year disease-free survival (DFS) was $70.83 \%$ in the 24 patients with unmethylated RUNX3, and 5.88\% in the 17 patients with RUNX3 methylation. Kaplan-Meier survival curves showed that the survival rates of patients with methylated RUNX3 were significantly worse than that of patients with unmethylated RUNX3 ( $\mathrm{P}=0.001$; log-rank test) (Fig. 5). 
Table III. Relationship between runt-related transcription factor-3 (RUNX3) protein expression and clinicopathological parameters in 19 frozen adenoid cystic carcinomas specimens.

\begin{tabular}{|c|c|c|c|}
\hline $\begin{array}{l}\text { Clinicopathological } \\
\text { parameters }\end{array}$ & $\begin{array}{l}\text { No. of } \\
\text { cases }\end{array}$ & $\begin{array}{c}\text { Protein } \\
\text { expression }\end{array}$ & P-value \\
\hline \multicolumn{4}{|l|}{ Specimen } \\
\hline Tumor & 19 & $0.49 \pm 0.05$ & \multirow[t]{2}{*}{$0.020^{\mathrm{a}}$} \\
\hline Normal & 19 & $0.79 \pm 0.03$ & \\
\hline \multicolumn{4}{|l|}{ Gender } \\
\hline Male & 13 & $0.51 \pm 0.05$ & \multirow[t]{2}{*}{0.525} \\
\hline Female & 6 & $0.44 \pm 0.13$ & \\
\hline \multicolumn{4}{|l|}{ Age at diagnosis (years) } \\
\hline$<57$ & 9 & $0.49 \pm 0.07$ & \multirow[t]{2}{*}{0.963} \\
\hline$\geq 57$ & 10 & $0.49 \pm 0.08$ & \\
\hline \multicolumn{4}{|l|}{ Tumor site } \\
\hline Minor salivary gland & 10 & $0.54 \pm 0.07$ & \multirow[t]{2}{*}{0.367} \\
\hline Major salivary gland & 9 & $0.44 \pm 0.08$ & \\
\hline \multicolumn{4}{|l|}{ Histologic types } \\
\hline Cribriform & 8 & $0.49 \pm 0.08$ & \multirow[t]{3}{*}{0.822} \\
\hline Tubular & 3 & $0.42 \pm 0.16$ & \\
\hline Solid & 8 & $0.52 \pm 0.08$ & \\
\hline \multicolumn{4}{|l|}{ Perineural invasion } \\
\hline Negative & 8 & $0.53 \pm 0.08$ & \multirow[t]{2}{*}{0.399} \\
\hline Positive & 11 & $0.44 \pm 0.06$ & \\
\hline \multicolumn{4}{|l|}{$\begin{array}{l}\text { Lymph node } \\
\text { involvement }\end{array}$} \\
\hline N0 & 13 & $0.60 \pm 0.08$ & \multirow[t]{2}{*}{0.172} \\
\hline $\mathrm{N}+$ & 6 & $0.44 \pm 0.06$ & \\
\hline \multicolumn{4}{|l|}{ T-stage } \\
\hline $\mathrm{T} 1-3$ & 14 & $0.70 \pm 0.05$ & \multirow[t]{2}{*}{$0.012^{\mathrm{a}}$} \\
\hline $\mathrm{T} 4$ & 5 & $0.42 \pm 0.21$ & \\
\hline \multicolumn{4}{|l|}{ Distant metastasis } \\
\hline Negative & 16 & $0.76 \pm 0.05$ & \multirow[t]{2}{*}{$0.020^{\mathrm{a}}$} \\
\hline Positive & 3 & $0.44 \pm 0.05$ & \\
\hline
\end{tabular}

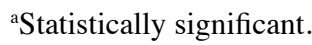

However, no significant association between overall survival and gender $(\mathrm{P}=0.985)$ or age $(\mathrm{P}=0.097)$ or tumor site $(\mathrm{P}=0.727)$ or solid histotype $(\mathrm{P}=0.645)$ or distant metastasis $(\mathrm{P}=0.843)$ or perineural invasion $(\mathrm{P}=0.379)$ or lymph node involvement $(\mathrm{P}=0.558)$ or $\mathrm{T}$-phage $(\mathrm{P}=0.782)$ was found. Multivariate survival analysis revealed that only RUNX3 methylation was an independent significant prognostic factor $(\mathrm{P}=0.011$; Cox-regression, Table V) for ACC patients after surgery.

\section{Discussion}

The genesis and development of ACC involve multiple genes and multiple steps, whose molecular bases are the activation of oncogenes and/or the inactivation of tumor-suppressor genes. DNA methylation plays important roles in gene expression regulation and cell proliferation, differentiation and develop-

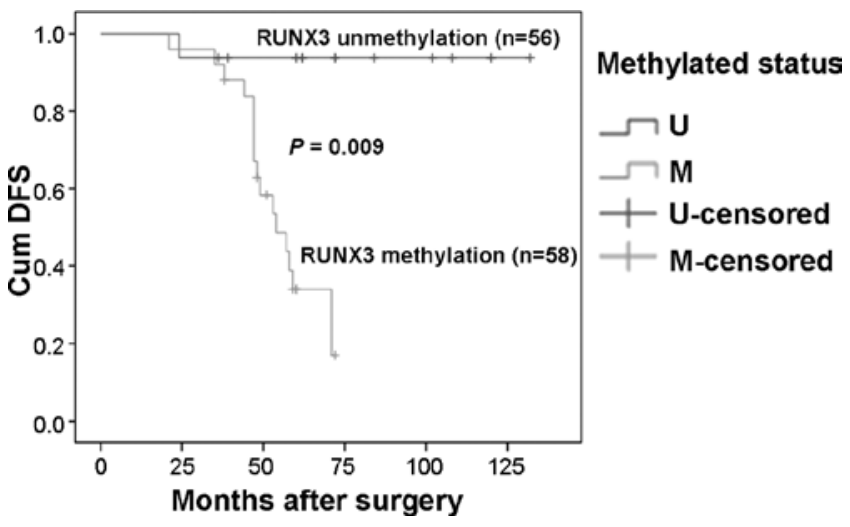

Figure 5. Comparison of disease-free survival curves for patients with RUNX3 promoter methylation.

ment, and methylation is closely related to the genesis and development of tumors (35-37). This study demonstrated that RUNX3 was expressed in ACC- 2 and ACC-3 cells, but no RUNX3 mRNA or protein was expressed in ACC-M cells from advanced lung metastases. After cells were treated with 5-Aza-dC, the expression of RUNX3 mRNA and protein was present in ACC-M cells and was increased in both ACC-2 and ACC-3 cells. 5-Aza-dC, a deoxycytidine analogue and a DNMT1 inhibitor, can covalently bind to DNA methyltransferase during DNA replication to reduce the activity of DNA methyltransferase. The result of this interaction is the inhibition of abnormal methylation of gene $\mathrm{CpG}$ islands and the activity of histone deacetylase in demethylation and restoration of the function of tumor-suppressor genes. Thus, the final result is the inhibition of tumor growth (38). The present study suggests that a decrease in or deficiency of RUNX3 expression in ACC cells may be caused by the methylation of $\mathrm{CpG}$ islands in the RUNX3 promoter region; 5-Aza-dC may help the inactivated RUNX3 gene to become demethylated, thus allowing RUNX3 to be re-expressed and thus restoring its tumor-suppressor function. This hypothesis was confirmed by RUNX3 methylation experiments. The ACC-M cell line screened from ACC-2 cell lines has a high rate of lung metastasis, while RUNX3 expression deficiency is associated with tumor invasiveness and metastasis $(39,40)$, suggesting that the high invasiveness of lung metastasis in ACC-M cells is linked to RUNX3 expression deficiency. The results suggested that RUNX3 expression can serve as an indicator for ACC invasiveness.

LSCM results showed RUNX3 protein was mostly expressed in the cytoplasm of ACC-2 and ACC-M cells, but low expression of RUNX3 was also noted in the nucleus of ACC-3 cells. Following treatment with 5-Aza-dC, RUNX3 protein expression was increased in the cytoplasm of all cells tested; RUNX3 protein was noted in the nucleus of ACC- 2 cells, while RUNX3 protein expression in ACC-M cells was cytoplasmic. RUNX3 protein is an important downstream regulatory factor in the TGF- $\beta$-mediated apoptosis signaling pathway. TGF- $\beta$ signal transduction in cells is mainly mediated by the Smad protein; RUNX protein binding to R-Smad (Smad2 and Smad3) has an important effect on TGF- $\beta$ signal transduction (41-45). Zaidi et al (46) reported that activated Smad protein complexes in TGF- $\beta$ signal transduction can be transferred from the cytoplasm 
Table IV. Univariate survival analysis of clinicopathologic data of 114 adenoid cystic carcinoma cases.

\begin{tabular}{lccc}
\hline Variables & Hazard ratio & 95\% confidence interval & P-value \\
\hline Age (<57/ $\geq 57$ years) & 0.44 & $0.161-1.204$ & 0.110 \\
Gender (female/male) & 1.009 & $0.383-2.658$ & 0.985 \\
Site (Major/Minor) & 1.192 & $0.440-3.228$ & 0.730 \\
T-stage (1-3/4) & 1.142 & $0.440-2.968$ & 0.785 \\
Histotypes (cribriform/tubular/solid) & 1.026 & $0.593-1.775$ & 0.927 \\
Distant metastasis (+/-) & 1.119 & $0.364-3.441$ & 0.845 \\
Perineural invasion (+/-) & 1.532 & $0.582-4.033$ & 0.388 \\
Lymph node involvement (+/-) & 1.341 & $0.496-3.630$ & 0.563 \\
RUNX3 (M/U) & 15.649 & $2.015-121.515$ & $0.009^{\mathrm{a}}$ \\
\hline
\end{tabular}

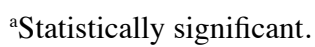

Table V. Multivariate survival analysis of clinicopathologic data of 114 adenoid cystic carcinoma cases.

\begin{tabular}{lccc}
\hline Variables & Hazard ratio & 95\% confidence interval & P-value \\
\hline Age (<57/ $\geq 57$ years) & 1.678 & $0.487-5.779$ & 0.412 \\
Gender (female/male) & 0.611 & $0.167-2.241$ & 0.458 \\
Site (Major/Minor) & 1.219 & $0.347-4.284$ & 0.758 \\
T-phage (1-3/4) & 0.952 & $0.484-1.873$ & 0.887 \\
Histotypes (cribriform/tubular/solid) & 1.468 & $0.218-9.871$ & 0.693 \\
Distant metastasis (+/-) & 1.806 & $0.568-5.742$ & 0.317 \\
Perineural invasion (+/-) & 0.632 & $0.110-3.634$ & 0.607 \\
Lymph node involvement (+/-) & 0.885 & $0.256-3.064$ & 0.848 \\
RUNX3 (M/U) & 15.237 & $1.853-125.304$ & $0.011^{\mathrm{a}}$ \\
\hline
\end{tabular}

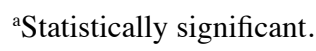

to nuclear-specific target sites under the guidance of RUNX proteins (including RUNX3). Together with RUNX proteins, the activated Smad protein complexes activate the transcription of target genes to regulate cell differentiation, cell cycling, apoptosis and malignant transformation. These results suggest that RUNX3 protein expression in the cytoplasm of ACC cells is associated with the genesis and development of tumors. The present study found that ectopic expression of RUNX3 protein in the cytoplasm of tumor cells is also an important mechanism of tumorigenesis of various tumor types. Current explanations for this mechanism focus on the following two points. i) Since one or more relevant factors inactivate the TGF- $\beta$ signaling pathway, RUNX3 proteins that accumulate in large numbers in the cytoplasm cannot be transferred to the nucleus, thus failing to activate target genes and inducing cellular apoptosis, leading to tumorigenesis. ii) It has been hypothesized that the structural changes of RUNX3 protein leading to dysfunction is the cause for RUNX3 protein accumulation in the cytoplasm (47). Ectopic expression of RUNX3 protein was noted in the cytoplasm of tumor cells, rather than an inhibition of the RUNX3 tumorsuppressor gene. Adequate experimental evidence to elucidate this issue is lacking.
This study used real-time MSP to detect RUNX3 methylation in 114 cases of ACC and in adjacent NSGs. The results showed that the degree of methylation in the ACC samples was significantly higher than that in the NSGs, which is consistent with data from several previous studies (48-50). These results suggest that RUNX3 promoter methylation plays an important role in the genesis and development of ACC. It was demonstrated that RUNX3 methylation was significant correlated with clinicopathological parameters, such as clinical stage, nerve invasion, lymph node metastasis and distant metastasis; however, no correlation with gender, age, tumor site and histologic types was noted. These results are consistent with those in the literature which report that 'RUNX3 methylation has significant correlation with tumor progression and prognosis' $(12,51-54)$. The degree of RUNX3 methylation in 19 cases of frozen ACC specimens was significantly related with the down-regulation of mRNA and protein of RUNX3, suggesting RUNX3 methylation may be a key mechanism for RUNX3 inactivation in the genesis and progression of ACC.

In the present study RUNX3 protein expression was significantly correlated with distant metastasis and $\mathrm{T}$ stage, and 
RUNX3 protein expression in metastatic ACC was significantly higher than that in the ACC cases without distant metastases. Research has shown that ectopic expression of RUNX3 protein, regardless of RUNX3 methylation, is always apparent in the cytoplasm of tumors. Therefore, ectopic expression of RUNX3 protein in the cytoplasm may play an oncogenic role $(8,11,12,24,54,55)$, but the exact mechanism involved remains to be elucidated. The results of this study also suggest that the ectopic expression of RUNX3 protein in the cytoplasm may also play an important role during ACC progression. Generally, RUNX3 methylation in ACC is an important cause of the down-regulation or deficiency of RUNX3 protein expression, and inhibition of RUNX3 expression has been correlated with prognosis of patients, which is similar to previous reports $(56,57)$. We found that the RUNX3 methylation was significantly related with overall survival $(\mathrm{P}=0.001$, log-rank test; $\mathrm{P}=0.009$, Cox-regression). Meanwhile, in the Cox multivariate survival analysis, there was significant association between RUNX3 methylation and overall survival $(\mathrm{P}=0.011)$. Therefore, RUNX3 may be a candidate as a prognostic marker and a molecular therapeutic target for salivary ACC, providing a new approach for the diagnosis and treatment of ACC (58). This trend warrants further investigation and statistical evaluation in a larger series of patients with a longer follow-up period. However, the regulation of RUNX3 expression, the mechanisms of RUNX3 transcription factors and whether or not the RUNX3 inter-relates with other oncogenes and/or tumor-suppressor genes are still undetermined. Re-expression of RUNX3 in ACC-M cells from advanced lung metastases can be induced by $5-\mathrm{Aza}-\mathrm{dC}$, and this expression may inhibit the proliferation of cancer cells. 5-Aza-dC is a promising potential treatment for ACC.

\section{Acknowledgements}

This study was supported by a grant from the Natural Science Foundation of Zhejiang Province, China (no. Y2080660), a grant from the Zhejiang Provincial Program for the Cultivation of High-level Innovative Health talents, and a grant from the Science and Technology General Project of Zhejiang Province (no. 2009C33116).

\section{References}

1. Rapidis AD, Givalos N, Gakiopoulou H, Faratzis G, Stavrianos SD, Vilos GA, Douzinas EE and Patsouris E: Adenoid cystic carcinoma of the head and neck. Clinicopathological analysis of 23 patients and review of the literature. Oral Oncol 41: 328-335, 2005.

2. Sung MW, Kim KH, Kim JW, Min YG, Seong WJ, Roh JL, Lee SJ, Kwon TK and Park SW: Clinicopathologic predictors and impact of distant metastasis from adenoid cystic carcinoma of the head and neck. Arch Otolaryngol Head Neck Surg 129: 1193-1197, 2003.

3. Spiro RH, Huvos AG and Strong EW: Adenoid cystic carcinoma of salivary origin. A clinicopathologic study of 242 cases. Am J Surg 128: 512-520, 1974.

4. Kim KH, Sung MW, Chung PS, Rhee CS, Park CI and Kim WH: Adenoid cystic carcinoma of the head and neck. Arch Otolaryngol Head Neck Surg 120: 721-726, 1994.

5. Spiro RH, Huvos AG and Strong EW: Adenoid cystic carcinoma: factors influencing survival. Am J Surg 138: 579-583, 1979.

6. Garden AS, Weber RS, Morrison WH, Ang KK and Peters LJ: The influence of positive margins and nerve invasion in adenoid cystic carcinoma of the head and neck treated with surgery and radiation. Int J Radiat Oncol Biol Phys 32: 619-626, 1995.
7. Parsons JT, Mendenhall WM, Stringer SP, Cassisi NJ and Million RR: Managements of minor salivary gland carcinomas. Int J Radiat Oncol Biol Phys 35: 443-454, 1996.

8. Li QL, Ito K, Sakakura C, Fukamachi H, Inoue K, Chi XZ, Lee KY, Nomura S, Lee CW, Han SB, Kim HM, Kim WJ, Yamamoto $\mathrm{H}$, Yamashita $\mathrm{N}$, Yano $\mathrm{T}$, Ikeda $\mathrm{T}$, Itohara $\mathrm{S}$, Inazawa J, Abe T, Hagiwara A, Yamagishi H, Ooe A, Kaneda A, Sugimura T, Ushijima T, Bae SC and Ito Y: Causal relationship between the loss of RUNX3 expression and gastric cancer. Cell 109: 113-124, 2002.

9. Ito Y: Oncogenic potential of the RUNX gene family: 'overview'. Oncogene 23: 4198-4208, 2004.

10. Chi XZ, Yang JO, Lee KY, Ito K, Sakakura C, Li QL, Kim HR, Cha EJ, Lee YH, Kaneda A, Ushijima T, Kim WJ, Ito Y and Bae SC: RUNX3 suppresses gastric epithelial cell growth by inducing p21[WAF1/Cip1] expression in cooperation with transforming growth factor \{beta\}-activated SMAD. Mol Cell Biol 25: 8097-8107, 2005.

11. Ito K, Liu Q, Salto-Tellez M, Yano T, Tada K, Ida H, Huang C, Shah N, Inoue M, Rajnakova A, Hiong KC, Peh BK, Han HC, Ito T, Teh M, Yeoh KG and Ito Y: RUNX3, a novel tumor suppressor, is frequently inactivated in gastric cancer by protein mislocalization. Cancer Res 65: 7743-7750, 2005.

12. Kim WJ, Kim EJ, Jeong P, Quan C, Kim J, Li QL, Yang JO, Ito $\mathrm{Y}$ and Bae SC: RUNX3 inactivation by point mutations and aberrant DNA methylation in bladder tumors. Cancer Res 65: 9347-9354, 2005.

13. Blyth K, Cameron ER and Neil JC: The RUNX3 genes: gain or loss of function in cancer. Nat Rev Cancer 5: 376-387, 2005.

14. Mori T, Nomoto S, Koshikawa K, Fujii T, Sakai M, Nishikawa Y, Inoue S, Takeda S, Kaneko T and Nakao A: Decreased expression and frequent allelic inactivation of the RUNX3 gene at 1 1p36 in human hepatocellular carcinoma. Liver Int 25: 380-388, 2005.

15. Nevadunsky NS, Barbieri JS, Kwong J, Merritt MA, Welch WR, Berkowitz RS and Mok SC: RUNX3 protein is overexpressed in human epithelial ovarian cancer. Gynecol Oncol 112: 325-330, 2009.

16. Fukamachi $\mathrm{H}$, Ito $\mathrm{K}$ and Ito $\mathrm{Y}$ : Run $\times 3^{-/}$gastric epithelial cells differentiate into intestinal type cells. Biochem Biophys Res Commun 321: 58-64, 2004

17. Miyasono K, Suzuki H and Imamura T: Regulation of TGF-beta signaling and its roles in progression of tumors. Cancer Sci 94: 230-234, 2003.

18. Fukamachi H: Runx 3 controls growth and differentiation of gastric epithelial cells in mammals. Dev Growth Differ 48: 1-13, 2006.

19. Suzuki M, Shigematsu H, Shames DS, Sunaga N, Takahashi T, Shivapurkar N, Iizasa T, Frenkel EP, Minna JD, Fujisawa T and Gazdar AF: DNA methylation-associated inactivation of TGFbeta-related genes DRM/Gremlin, RUNX3, and HPP1 in human cancers. Br J Cancer 93: 1029-1037, 2005.

20. Tozawa T, Tamura G, Honda T, Nawata S, Kimura W, Makino N, Kawata S, Sugai T, Suto T and Motoyama T: Promoter hypermethylation of DAP-kinase is associated with poor survival in primary biliary tract carcinoma patients. Cancer Sci 95: 736-740, 2004.

21. Ogi K, Toyota M, Ohe-Toyota M, Tanaka N, Noguchi M, Sonoda T, Kohama G and Tokino T: Aberrant methylation of multiple genes and clinicopathological features in oral squamous cell carcinoma. Clin Cancer Res 8: 3164-3171, 2003.

22. Yang Q, Zage P, Kagan D, Tian Y, Seshadri R, Salwen HR, Liu S, Chlenski A and Cohn SL: Association of epigenetic inactivation of RASSF1A with poor outcome in human neuroblastoma. Clin Cancer Res 10: 8493-8500, 2004.

23. Ku JL, Kang SB, Shin YK, Kang HC, Hong SH, Kim IJ, Shin JH, Han IO and Park JG: Promoter hypermethylation down-regulates RUNX3 gene expression in colorectal cancer cell lines. Oncogene 23: 6736-6742, 2004.

24. Lau QC, Raja E, Salto-Tellez M, Liu Q, Ito K, Inoue M, Putti TC, Loh M, Ko TK, Huang C, Bhalla KN, Zhu T, Ito Y and Sukumar S: RUNX3 is frequently inactivated by dual mechanisms of protein mislocalization and promoter hypermethylation in breast cancer. Cancer Res 66: 6512-6520, 2006.

25. Li J, El-Naggar A and Mao L: Promoter methylation of P16INK4a, RASSF1A, and DAPK is frequent in salivary adenoid cystic carcinoma. Cancer 104: 771-776, 2005.

26. Maruya S, Kurotaki H, Wada R, Saku T, Shinkawa H and Yagihashi S: Promoter methylation and protein expression of the E-cadherin gene in the clinicopathologic assessment of adenoid cystic carcinoma. Mod Pathol 17: 637-645, 2004. 
27. Zhang CY, Mao L, Li L, Tian Z, Zhou XJ, Zhang ZY and Li J: Promoter methylation as a common mechanism for inactivating E-cadherin in human salivary gland adenoid cystic carcinoma. Cancer 110: 87-95, 2007.

28. Guan XF, Qiu WL and He RG: The selection of high lung metastasis salivary adenoid cystic carcinoma clone. Chin J Stomatol 3: 74-77, 1996.

29. He RG, Zhang XS and Zhou XJ: The establishment of cell lines of adenoid cystic carcinoma of human salivary glands (ACC-2, ACC-3) and a study of morphology. West China J Stomatol 6: $1-4,1988$.

30. Wittekind C, Compton CC, Greene FL and Sobin LH: TNM residual tumor classification revisited. Cancer 94: 2511-2516, 2002.

31. Ling ZQ, Sugihara H, Tatsuta T, Mukaisho K and Hattori T: Optimization of comparative expressed sequence hybridization for genome-wide expression profiling at chromosome level. Cancer Genet Cytogenet 175: 144-153, 2007.

32. Waki T, Tamura G, Sato M, Terashima M, Nishizuka S and Motoyama T: Promoter methylation status of DAP-kinase and RUNX3 genes in neoplastic and non-neoplastic gastric epithelia. Cancer Sci 94: 360-364, 2003.

33. Homma N, Tamura G, Honda T, Matsumoto Y, Nishizuka S, Kawata $S$ and Motoyama T: Spreading of methylation within RUNX3 CpG island in gastric cancer. Cancer Sci 97: 51-56, 2006

34. Noble JE and Bailey MJ: Quantitation of protein. Meth Enzymol 463: 73-95, 2009.

35. Ehrlich M: The controversial denouement of vertebrate DNA methylation research. Biochemistry 70: 568-575, 2005.

36. Pufulete M, Al-Ghnaniem R, Rennie JA, Appleby P, Harris N, Gout S, Emery PW and Sanders TA: Influence of folate status on genomic DNA methylation in colonic mucosa of subjects without colorectal adenoma or cancer. Br J Cancer 92: 838-842, 2005.

37. Kim TY, Jong HS, Jung Y, Kim TY, Kang GH and Bang YJ: DNA hypermethylation in gastric cancer. Aliment Pharmacol Ther 20: 131-142, 2004.

38. Cameron EE, Bachman KE, Myöhänen S, Herman JG and Baylin SB: Synergy of demethylation and histone deacetylase inhibition in the re-expression of genes silenced in cancer. Nat Genet 21: 103-107, 1999.

39. Wei D, Gong W, Oh SC, Li Q, Kim WD, Wang L, Le X, Yao J, Wu TT, Huang S and Xie K: Loss of RUNX3 expression significantly affects the clinical outcome of gastric cancer patients and its restoration causes drastic suppression of tumor growth and metastasis. Cancer Res 65: 4809-4816, 2005.

40. Sakakura C, Hasegawa K, Miyagawa K, Nakashima S, Yoshikawa T, Kin S, Nakase Y, Yazumi S, Yamagishi H, Okanoue T, Chiba T and Hagiwara A: Possible involvement of RUNX3 silencing in the peritoneal metastases of gastric cancers. Clin Cancer Res 11: 6479-6788, 2005.

41. Derynck R, Akhurst RJ and Balmain A: TGF- $\beta$ signaling in tumor suppression and cancer progression. Nat Genet 29: $117-129,2001$

42. Fukamachi $\mathrm{H}$ and Ito $\mathrm{K}$ : Growth regulation of gastric epithelial cells by Runx3. Oncogene 23: 4330-4335, 2004.

43. Ito $\mathrm{Y}$ and Miyazono K: RUNX transcription factors as key targets of TGF- $\beta$ superfamily signaling. Curr Opin Genet Dev 13: 43-47, 2003.
44. Torquati A, O'rear L, Longobardi L, Spagnoli A, Richards WO and Daniel Beauchamp R: RUNX3 inhibits cell proliferation and induces apoptosis by reinstating transforming growth factor beta responsiveness in esophageal adenocarcinoma cells. Surgery 136: 310-316, 2004.

45. Park SR, Lee EK, Kim BC and Kim PH: p300 cooperates with Smad3/4 and Runx3 in TGFbeta1-induced IgA isotype expression. Eur J Immunol 33: 3386-3392, 2003.

46. Zaidi SK, Sullivan AJ, van Wijnen AJ, Stein JL, Stein GS and Lian JB: Integration of RUNX and Smad regulatory signals at transcriptionally active subnuclear site. Proc Natl Acad Sci USA 99: 8048-8053, 2002.

47. Tsunematsu T, Kudo Y, Iizuka S, Ogawa I, Fujita T, Kurihara H, Abiko Y and Takata T: RUNX3 has an oncogenic role in head and neck cancer. PLoS One 4: e5892, 2009.

48. So K, Tamura G, Honda T, Homma N, Waki T, Togawa N, Nishizuka S and Motoyama T: Multiple tumor suppressor genes are increasingly methylated with age in non-neoplastic gastric epithelia. Cancer Sci 97: 1155-1158, 2006.

49. Chen W, Gao N, Shen Y and Cen JN: Hypermethylation downregulates Runx3 gene expression and its restoration suppresses gastric epithelial cell growth by inducing p27 and caspase 3 in human gastric cancer. J Gastroenterol Hepatol 25: 823-831, 2010.

50. Tamura G,So K, Miyoshi H,Honda T,Nishizuka S and Motoyama T: Quantitative assessment of gene methylation in neoplastic and non-neoplastic gastric epithelia using methylation-specific DNA microarray. Pathol Int 59: 895-899, 2009.

51. Gao F, Huang C, Lin M, Wang Z, Shen J, Zhang H, Jiang L and Chen Q: Frequent inactivation of RUNX3 by promoter hypermethylation and protein mislocalization in oral squamous cell carcinomas. J Cancer Res Clin Oncol 135: 739-747, 2009

52. Nomoto S, Kinoshita T, Mori T, Kato K, Sugimoto H, Kanazumi N, Takeda S and Nakao A: Adverse prognosis of epigenetic inactivation in RUNX3 gene in 1 p36 in human pancreatic cancer. Br J Cancer 98: 1690-1695, 2008

53. Sato K, Tomizawa Y, Iijima H, Saito R, Ishizuka T, Nakajima T and Mori M: Epigenetic inactivation of the RUNX3 gene in lung cancer. Oncol Rep 15: 129-135, 2006.

54. Kim EJ, Kim YJ, Jeong P, Ha YS, Bae SC and Kim WJ: Methylation of the RUNX3 promoter as a potential prognoistic marker for bladder tumor. J Urol 180: 806-807, 2008.

55. Chuang LS and Ito Y: RUNX3 is multifunctional in carcinogenesis of multiple solid tumors. Oncogene 29: 2605-2615, 2010.

56. Kim EJ, Kim YJ, Jeong P, Ha YS, Bae SC and Kim WJ: Methylation of the RUNX3 promoter as a potential prognostic marker for bladder tumor. J Urol 180: 1141-1145, 2008.

57. Jiang Y, Tong D, Lou G, Zhang Y and Geng J: Expression of RUNX3 gene, methylation status and clinicopathological significance in breast cancer and breast cancer cell lines. Pathobiology 75: 244-251, 2008

58. He JF, Ge MH, Zhu X, Chen C, Tan Z, Li YN and Gu ZY: Expression of RUNX3 in salivary adenoid cystic carcinoma: Implications for tumor progression and prognosis. Cancer Sci 99: 1334-1340, 2008. 